\title{
Dynamic Economic Dispatch of Microgrid with Biomass Power Generation
}

\author{
Liang Shuiying ${ }^{1, a}$, Zhu Jing ${ }^{2, b}$ \\ ${ }^{1}$ Guangxi Power Grid Electric Power Research Institute, Nanning, 530023, Guangxi Zhuang \\ Autonomous Region, China \\ ${ }^{2}$ Nanning Distribution Network Automation System, Nanning, 530031, Guangxi Zhuang \\ Autonomous Region, China \\ aliang_sy.sy@gx.csg.cn \\ b178475581@qq.com
}

\begin{abstract}
Keywords: Micro-grid; Dynamic Economic Dispatch; Biomass energy; Biogas power generation; bagasse power generation

Abstract. Biomass energy is an important distributed generations and energy production, biomass energy utilization rate is very high. This paper focuses on the biomass power generation, photovoltaic power generation conditions, the load characteristics in Guangxi rural areas, were all analyzed by statistics, build a mathematical model of biogas power generation and bagasse power generation base on the statistics. According to different characteristics of the climate in summer and winter, with the grid and island two operation modes, propose the model of dynamic economic dispatch including the biomass generations, on the basis of subsidies for renewable energy prices, this model takes the minimum cost of power generation as the objective, in summer the biogas power generation and photovoltaic power generation as the main power supply, in the winter , the bagasse as the main power supply power, diesel generator as the load reserve function. The simulation results show that the model can fully evaluate the economy of distributed power users to meet the diverse needs, in order to help users to determine the system economic operation scheme.
\end{abstract}

\section{Introduction}

Now the world is facing a severe challenges, Population, resources, food, environmental problems and the shortage of oil, coal and other energy, those can be the serious problem. To develop biomass energy to gradually replace fossil energy industry is a strategic decision [1] Biomass energy as the fourth kind of energy, Mainly concentrated in the rural areas, in the form of distributed power supply. As the complement of centralized power generation, distributed generation and its system integration technology has been mature, is an important way of electricity production in the future. State Grid released "Opinions on Distributed Power Grid Service" in February 2013[2], to promote the development of distributed power supply in our country. With the rapid development of the Beibuwan economic region, Lacking of coal, power shortage problem in Guangxi will be increasingly severe; Biomass power generation will meet a great development opportunities and challenges[3-4].

Biomass energy gets the advantages of without being limited by the area and with the high energy efficiency, and it is more suitable than solar and wind power for vast territory, large population and unbalance distribution national conditions. Biomass energy as the fourth kind of energy in our country, it has a great potential, but the research is still in the stage in currently, and few research results. Paper[5-7] introduces the types of biomass resources and the main way of generating, describes the economic and energy saving effect, and propose the suggestions of the development of biomass power generation. Paper[8] compares and analysis the theory of value of five types of the typical biomass power generation system, it is concluded that the energy of the biomass power generation system output force are higher than that of coal-fired power generation, and the environmental load rates are low. Paper[9] consider rural load characteristic and the uncertainty of the new energy output, through the evaluation of the economic environment under the premise of reliability and technical index, respectively to two combination of new energy, and single power 
supply model to evaluate the contrast, it is concluded that for new energy power generation mix. Paper[10] analyze community load and natural resources of remote area, put forward with the wind, wood, storage, biomass power generation of micro power supply system, and Compare with the existing diesel power supply system then optimal design scheme is feasible. The research of the literature on biomass power generation has made gradual progress, but still need to consider the following two aspects:

(1) Analytical mathematical modeling of various kinds of biomass. According to the characteristics and the way of transformation, different biomass get different form of power generation and power efficiency, only accurate expression can better using.

(2) Biomass is one of a distributed power supply, when access In the low voltage distribution network, permeability is getting higher, it needs to through micro network technology so as to realize the balance of power distribution network and safe operation, and ensure that the user power supply reliability and power quality.

The above two problems involved in the study of the early stage of the biomass. Integrated above problem, this paper has been investigated the typical biogas power generation and bagasse power engineering, and establish a mathematic model of the two kinds of direct-fired biomass power generation; In considering the basis of the load characteristics, climatic conditions, and energy production, and propose the power generation micro network dynamic scheduling model which can meet he demand of rural load, giving the optimize power supply output results. of grid and island mode on the minimum cost as the objective function.

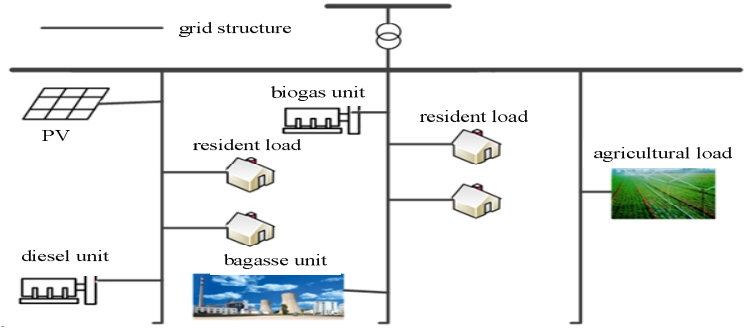

Figure 1. Configuration of the microgrid system

\section{Microgrid with biomass Power Generation}

Micro network technology can achieve large-scale access to distributed power in the low-voltage distribution network, solve the problem of power supply radius, low reliability and high dissipation in rural[11]. Including biogas power generation and bagasse power network structure as shown in figure 1, figure of distributed power supply also contain photovoltaic power generation, diesel generator, in the form of cogeneration joint supply power to load. Based on the distributed power system characteristics and load characteristic, comparing the micro source of power generation cost and large online electricity price, and respectively discusses micro-grid in grid economic operation characteristics and island.

Increase the biomass power generation capacity can effectively improve the stability of micro network operation and reduce the degree of dependence, In the case of allow delivers the power, the advantage of reasonable use sell electricity prices to micro bring economic, environmental and other benefits. But on the other hand, because of the biogas fermentation gas production rate is significantly higher than in winter, summer bagasse generator run only in the winter, and micro economy and biomass of a power supply is directly related to the installed capacity. Visible, synthesizes under the premise of biomass power generation model and other factors, analysis of different season optimized configuration scheme for micro network capacity is a problem worthy of in-depth discussion. 


\section{A mathematical model of distributed power generation}

This paper study the micro network dynamic scheduling of optical, wood, biomass power generation, in terms of investigation to obtain first-hand data, modeling the biomass power generation in respectively.

\section{Biogas power generation}

The energy shortage in Guangxi cause rural power are short, but the new rural construction are creating an increasing demand for electricity, to analysis the resources and environment condition, it is suitable for universal using biogas power generation technology in rural areas where are in animal husbandry as the economic pillar industry and agriculture, forestry and raw material rich region, thus to promote the development of agriculture and animal husbandry, and farmers' incomes.

Taking 1MW gas power generation as research object in Guangxi, adopting Correl correlation for the pressure, power consumption and correlation analysis when Biogas power generation are stable operation, Correlation are 0.70, 0.72, With pressure and methane consumption as independent variables, the output power of the dependent variable, the model is as follows formula (1):

$$
P=\partial_{0}+\partial_{1} F_{1}++\partial_{2} F_{2}+\partial_{3} F_{1}^{2}
$$

in invariants: $\mathrm{P}$ denotes output power of biogas power generation, is $\mathrm{kW} ;{ }_{1},{ }_{2}$ denote pressure, gas consumption in respectively, unit are $\mathrm{kPa}, \mathrm{NM} 3 / \mathrm{h} ;{ }^{\partial_{0}}$ denotes the constant; ${ }^{\partial_{1}}, \partial_{2}$ denote pressure biogas power generation and gas consumption of linear coefficient; ${ }^{\partial_{3}}$ denotes the quadratic term coefficient. The parameters obtained from the fitting function respectively are $\partial_{0}=2338.10$, $\partial_{1}=323.42, \partial_{2}=8.46, \partial_{3}=26.05$.

\section{Bagasse power generation}

The advantages of bagasse power generation are less sulfur and ash content. For example, a $12 \mathrm{mw}$ bagasse power generation engineering, the power generation process is consistent with the traditional thermal power plant. the inlet pressure, bagasse consumption and the output power of the two boilers are $0.30,36$ and 0.89 by analyzing the correlation. The mathematical model of bagasse power generation was established with taking the inlet pressure and the bagasse consumption as the independent variable, and taking the output power as the dependent variable. The model of the BAG is similar to the model of the BIG that using the nonlinear regression analysis method. The model is as follows formula (2):

$$
\begin{aligned}
P= & \lambda_{0}+\lambda_{1} F_{1}+\lambda_{2} F_{2}+\lambda_{3} F_{3}+\lambda_{12} F_{1} F_{2} \\
& +\lambda_{4} F_{1}^{2}+\lambda_{5} F_{2}^{2}
\end{aligned}
$$

in invariants: $\mathrm{P}$ denotes output power of biogas power generation, is $\mathrm{kW} ;{ }_{1}, F_{2}, F_{3}$ denote the inlet pressure of the \# 1 steam turbine, the inlet pressure of the \# 2 boiler and the bagasse consumption in respectively, unit are MPa, T; ${ }^{\lambda_{0}}$ denotes the constant; $\lambda_{1}, \lambda_{2}, \lambda_{3}$ denote inlet pressure of the steam turbine and bagasse consumption of linear coefficient; ${ }^{\lambda}$ denotes the cross product coefficient of the turbine inlet pressure and bagasse consumption; $\lambda_{4}, \lambda_{5}$ denotes the quadratic term coefficient.

Taking the parameters of a factory in Hangzhou as an example, the parameters obtained from the fitting function: ${ }^{\lambda_{0}}$ is $23124.67,{ }^{\lambda_{1}}$ is $-9240.18,{ }^{\lambda_{2}}$ is $-923.21,{ }_{3}$ is $166.52,{ }_{12}$ is $3304.58,{ }^{\lambda_{4}}$ is -139.99 , $\lambda_{5}$ is -1392.17 .

\section{Photovoltaic power generation}

The photovoltaic (PV) model takes the effects of solar radiation intensity, ambient temperature and other factors into account. The output equation of photovoltaic power generation is formula (3) [12]:

$$
P=U\left\{I_{\mathrm{sc}}\left[1-c_{1}\left(\exp \frac{U-\Delta U}{c_{2} U_{o c}}-1\right)\right]+\Delta I\right\}
$$


in invariants: $\mathrm{P}$ denotes output power of photovoltaic power generation; $U$ denotes current output voltage; $I_{\text {sc }}$ denotes short-circuit current; ${ }^{c_{1}} 、 c_{2}$ are calculated by maximum power point $U=U_{m}, I=I_{m}$ and $I=0, U=U_{o c}$ of open circuit status; $U_{o c}$ denotes the open circuit voltage; $\Delta U$ denotes the amount of voltage change that is affected by light intensity and temperature; $\Delta I$ denotes the amount of current change that is affected by light intensity and temperature.

\section{Diesel engine power generation}

Diesel engine is usually used as a backup power supply, power generation efficiency increases with the output power, and reaches the maximum efficiency when the rated power is the biggest. The generator model is simplified and the linear function of fuel consumption $\mathrm{F}$ and its output power is related to[13,14]:

$$
F=F_{0} P_{\mathrm{g}} u+F_{1} P_{\mathrm{t}}
$$

in invariants : $F$ denotes fuel consumption, $F_{0}$ and $F_{1}$ denote curve intercept coefficient of diesel consumption; $P_{g}$ and $P_{t}$ denote rated power and output power of diesel generator; $u$ is the generator's boot state, 0 denotes shutdown, 1 denotes boot. Taking the value of $F_{0}$ to 0.08415 , and the value of $F_{1}$ to 0.246 according to the literature. The optimum load rate of a single diesel generator is about $75 \%$, the minimum load is usually about $30 \%$. If the value below $30 \%$, the fuel consumption of the diesel engine will increase and the operating life of the generator will be affected. The rated power is three times that of minimum operating power in this paper.

\section{Dynamic economic scheduling model of micro network}

\section{Objective function}

Grid-sharing objective function

Power generation costs of micro-grid operation are minimal. The microgrid system, which includes photovoltaic power generation, biomass power generation and diesel power generation, performs bidirectional power exchange through the feeder and the low voltage distribution network, and makes costs of the system be minimal. Don't take the distribution network loss into account. In order to make power generation costs of micro-grid operation be minimal, the objective function can be described as formula (5):

$$
\begin{aligned}
\min f_{\cos t}= & \beta_{1} \sum_{t=1}^{T} P_{B I G, t}+\beta_{2} \sum_{t=1}^{T} P_{P V, t} \\
& +\beta_{3} \sum_{t=1}^{T} P_{S P, t}+\beta_{4} \sum_{t=1}^{T} P_{D E, t}+\beta_{5} \sum_{t=1}^{T} P_{R L, t}
\end{aligned}
$$

in invariants: $f_{\text {cost }}$ denotes power generation costs of micro network; $T$ denotes Scheduling time; $P_{B I G, t}$ denotes the active power of the biogas unit at $\mathrm{t}$ moments; ${ }_{P V, t}$ denotes the active power of the photovoltaic generating units at $\mathrm{t}$ moments; ${ }_{S P, t}$ denotes the active power of the bagasse generators at $\mathrm{t}$ moments; $P_{D E, t}$ denotes the active power of the diesel generators at $\mathrm{t}$ moments; $P_{R L, t}$ denotes the active power that exchange between micro network and large grid; $\beta_{1}, \beta_{2}, \beta_{3}, \beta_{4}, \beta_{5}$ are power generation cost factors of BIG, PV, SP, DE, RL that government subsidies are considered.

Island objective function

If the supply of distributed power on the island is greater than the load demand on the island, and it also has a certain spare capacity, the system can run normally[15]. For non-energy storage micro grids, the optimal reserve capacity is set to exceed $20 \%$ of the load power requirement [16]. In this paper, diesel power generation is used as the reserve capacity. On the basis of formula (5), the island operation's objective function of the minimum running cost is proposed without considering the active power exchange with the distribution network. The objective function can be described as follows formula (6): 


$$
\min f_{\text {cost }}=\beta_{1} \sum_{t=1}^{T} P_{B I G, t}+\beta_{2} \sum_{t=1}^{T} P_{P V, t}+\beta_{3} \sum_{t=1}^{T} P_{S P, t}+\beta_{4} \sum_{t=1}^{T} P_{D E, t}
$$

\section{Constraints}

Grid-running constraints

(1) system power balance constraints as formula (7):

$$
P_{B I G, t}+P_{P V, t}+P_{S P, t}+P_{D E, t}+P_{R L, t}=P_{L O A D, t}
$$

Increase the output power constraints of the bagasse power plant below, take $5 \%$ of the bagasse power generation's maximum output as reserve load capacity in formula (8).

$$
\left\{\begin{array}{l}
P_{S P}=P_{B A G}-P_{A P} \\
P_{R P} \leq P_{B A G}-P_{A P}-P_{S P}
\end{array}\right.
$$

in invariants: $P_{L O A D, t}$ is the load value at $\mathrm{t}$ moments; $P_{R P}$ denotes spare load of bagasse power plant; $P_{S P}$ denotes power supply load of bagasse power generation in the micro network; $P_{A P}$ denotes plant load of bagasse power generation;

(2) Output constraints of units as formula (9)-(12):

$$
\begin{array}{r}
P_{B I G}^{\min } \leq P_{B I G, t} \leq P_{B I G}^{\max } \\
P_{P V}^{\min } \leq P_{P V, t} \leq P_{P V}^{\max } \\
P_{S P}^{\min } \leq P_{S P, t} \leq P_{S P}^{\max } \\
P_{D E}^{\min } \leq P_{D E, t} \leq P_{D E}^{\max }
\end{array}
$$

In the formula: $P_{i}^{\min }$ and $P_{i}^{\max }$ are the upper and lower limits of the units output respectively, $i$ denotes distributed generations.

(3) Constraints of fuel

The climatic conditions have a great influence on the production of fuel raw materials. Considering the large amount of sugar cane in Guangxi and the bagasse is sufficient for power generation, the amount of bagasse is not limited in this paper. Biogas constraints are described as follows formula (13):

$$
F_{B I G}^{\min } \leq F_{B I G} \leq F_{B I G}^{\max }
$$

\subsubsection{Island conditions}

The constraint of system power balance for the micro-grid island operation is formula (14):

$$
P_{B I G, t}+P_{P V, t}+P_{S P, t}+P_{D E, t}=P_{L O A D, t}
$$

The other constraints remain unchanged, so as to maintain the balance of system power in real time[17].

\section{Examples analysis}

Take IPOPT [18] to solve the model. IPOPT (Interior Point Optimizer) solver is designed to be able to solve nonlinear programming problems quickly.

\section{Basic data}

Yulin City is an important aquaculture production base in Guangxi, which sugarcane, silkworm mulberry, rice and other non-grain biomass resources are rich. So we take a village in Yulin, Guangxi as a research object. Micro-source installed capacity parameters micro network shown in Table1, the various types of distributed power generation costs that considering the price of subsidies are shown in Table 2. And Figure 1 shows the micro-grid structure of non-grain biomass power generation. The dynamic economic scheduling model that proposed in this paper is used to optimize the configuration based on the climatic conditions, non - grain biomass resources and electricity load demand of the village. 
Table1. System operation parameters of microgrid

\begin{tabular}{cccc}
\hline Types & $\begin{array}{l}\text { Installed } \\
\text { capacity } \\
/ \mathrm{kW}\end{array}$ & $\begin{array}{c}\text { Pmin } \\
/ \mathrm{kW}\end{array}$ & Pmax/kW \\
\hline $\mathrm{DE}$ & $2.5 * 432$ & 0 & 1080 \\
$\mathrm{BIG}$ & $500 * 2$ & 0 & 1000 \\
$\mathrm{BAG}$ & $\begin{array}{c}12000-P_{R P^{-}} \\
P_{A P}\end{array}$ & 0 & $12000-P_{R P}$ \\
$\mathrm{DE}$ & $500 * 2$ & 150 & $-P_{A P}$ \\
Power & & -4000 & 4000 \\
grid & $/$ & & \\
\hline
\end{tabular}

Table2. Power generation cost parameters

\begin{tabular}{cccc}
\hline $\begin{array}{c}\text { Power } \\
\text { supply } \\
\text { Type }\end{array}$ & $\begin{array}{c}\text { Average } \\
\text { costs of } \\
\text { power } \\
\text { generation } \\
\text { (yuan / } \\
\mathrm{kWh})\end{array}$ & $\begin{array}{c}\text { Subsidies } \\
\text { of power } \\
\text { generatio } \\
\mathrm{n}(\text { yuan / } \\
\mathrm{kWh})\end{array}$ & $\begin{array}{c}\text { Actual costs } \\
\text { of power } \\
\text { generation } \\
\text { (yuan / } \\
\mathrm{kWh})\end{array}$ \\
\hline Biogas & 0.60 & 0.15 & 0.45 \\
PV & 1.45 & 0.42 & 1.03 \\
Bagasse & 0.72 & 0.42 & 0.30 \\
$\begin{array}{c}\text { Buy } \\
\text { electricity } \\
\text { Selling } \\
\text { electricity } \\
\text { Diesel } \\
\text { engine }\end{array}$ & 0.54 & $/$ & 0.54 \\
\hline
\end{tabular}

(1) load demand analysis

The village's electricity load mainly includes residents' living load and agricultural production load. Figure 2 shows the typical daily load change in the summer and winter of 2014. This paper will make reasonable planning of distributed power output based on the typical daily load in summer and winter.

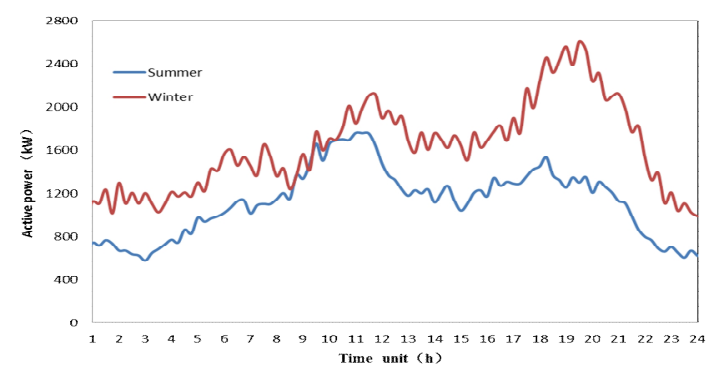

Figure 2. The typical daily load curve of summer and winter

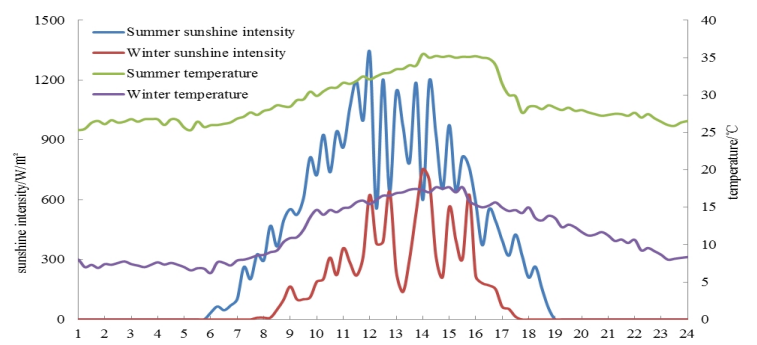

$t / h$

Figure 3. The typical daily sunshine intensity and temperature 
Table3. Household biogas potential methane content

\begin{tabular}{cccccc}
\hline Season & $\begin{array}{c}\text { Number of } \\
\text { household } \\
\mathrm{s}\end{array}$ & $\begin{array}{c}\text { Household rate } \\
\text { of } 8 \mathrm{~m}^{3} \text { biogas } \\
\text { digesters }\end{array}$ & $\begin{array}{c}\text { Househol } \\
\text { ds with } 4 \\
\text { pigs }\end{array}$ & $\begin{array}{c}\text { 1 pig's Gas } \\
\text { production } \\
\text { rate }\left(\mathrm{m}^{3} / \mathrm{d}\right)\end{array}$ & $\begin{array}{c}\text { potentia } \\
1 \text { biogas } \\
/ \mathrm{m}^{3}\end{array}$ \\
\hline $\begin{array}{c}\text { Summer } \\
\text { Winter }\end{array}$ & 1029 & 0.64 & 700 & 0.537 & 1505 \\
\hline
\end{tabular}

(2) Photovoltaic power generation conditions

Photovoltaic power generation is random, which does not directly consume fuel, and do not pollute the environment. In order to recover the cost of investment as soon as possible, so we give priority to its use [19].

Sunshine intensity and temperature curve shown in Figure 3, Cloudy weather is frequently in winter, which has larger sunshine changes and small sunshine intensity; the annual average temperature is between $16{ }^{\circ} \mathrm{C} \sim 23{ }^{\circ} \mathrm{C}$, temperature difference between summer and winter is larger, that can reach $20^{\circ} \mathrm{Csometimes.}$

(3) Analysis of biogas resources

Biogas resources are mainly from household biogas digesters and large-scale pig farms. Based on the estimated daily production of biogas in Guangxi, and the effect of temperature on biogas production, where the daily biogas production in winter is about 0.6 times of which in summer [20, 21]. The amount of potential biogas in rural household biogas can be calculated and shown in Table 3 .

We calculate the potential biogas according to the situation of the village, and the number of pigs is 20080. The amount of daily dry matter emissions can be calculated on the basis of population structure, excrement emissions and biogas production rate in large-scale pig farms. In summer and winter, the efficiency of biogas production that pig manure and straw were mixed according to certain ratio is higher than which of single fermentation feedstuffs [21, 22], and the potential biogas in summer and winter is shown in Table 4.

Table4. Farms biogas potential methane content

\begin{tabular}{|c|c|c|c|c|}
\hline Season & $\begin{array}{l}\text { dry matter } \\
\text { emissions per } \\
\text { day }(\mathrm{kg} \cdot \mathrm{TS})\end{array}$ & $\begin{array}{l}\text { single } \\
\text { fermentation } \\
\text { feedstuffs } \\
\left(\mathrm{m}^{3} / \mathrm{d}\right)\end{array}$ & $\begin{array}{l}\text { Mixing } \\
\text { gas rate } \\
\left(\mathrm{m}^{3} / \mathrm{d}\right)\end{array}$ & $\begin{array}{l}\text { potential } \\
\text { daily } \\
\text { biogas in } \\
\text { farms } / \mathrm{m}^{3}\end{array}$ \\
\hline Summer & 8239.6 & 0.45 & 1.08 & 8898 \\
\hline Winter & 8239.6 & 0.30 & 0.60 & 4943 \\
\hline \multicolumn{5}{|c|}{ Table5. Village biogas potential methane content } \\
\hline Season & $\begin{array}{l}\text { Household } \\
\text { biogas } \\
\left(\mathrm{m}^{3} / \mathrm{d}\right)\end{array}$ & $\begin{array}{l}\text { Farm biogas } \\
\left(\mathrm{m}^{3} / \mathrm{d}\right)\end{array}$ & $\begin{array}{l}\text { Biogas that } \\
\text { residents } \\
\text { use }\left(\mathrm{m}^{3} / \mathrm{d}\right)\end{array}$ & $\begin{array}{l}\text { Available } \\
\text { biogas } \\
\left(\mathrm{m}^{3} / \mathrm{d}\right)\end{array}$ \\
\hline Summer & 1505 & 8898 & 910 & 9493 \\
\hline Winter & 910 & 4943 & 910 & 4943 \\
\hline
\end{tabular}

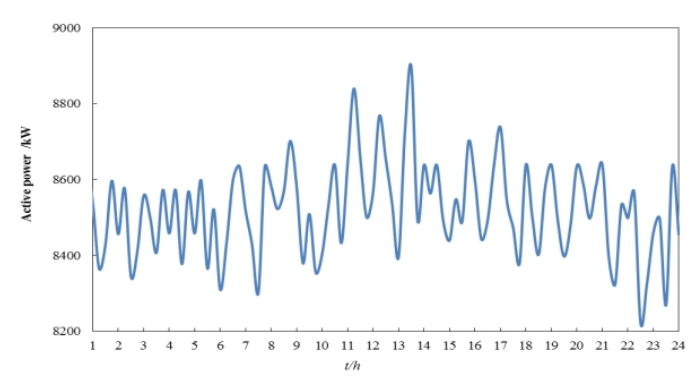

Figure 4. Typical power curve of Sugar industry 


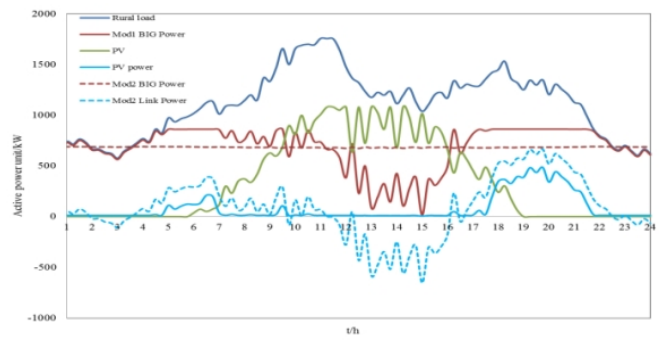

Figure 5. Microgrid summer output of different operating mode

Table 5 shows the potential daily biogas that can be used for power generation in summer and winter.

(4) Analysis of bagasse power generation

Bagasse power generation technology is mature, which the scale of installed capacity is large, and the output is stable. But generally only in the specific season (November to April next year), the bagasse power generation can provide adequate power supply. Typical daily electricity consumption curve shown in Figure 4 and Figure 5, which include the sugar refining, sugar cane press, machine repair and live electricity. Electricity can reach the about $80 \%$ of installed capacity.

\section{Analysis of dynamic economic scheduling results}

In order to explain the dynamic economic effect of the biomass power generation in micro network, we compare the power generation cost of micro network with the deviation between the planned value and the actual value of feeders.

Mode 1: Optimize the output of power supply in micro network each time period, which taking the various periods of load value, costs of micro-source power generation into account.

Mode 2: The output of biomass power generation is balanced at all times. The output of Biogas power generation takes the average of 24 hours; power factor of bagasse generators is 0.9 .

Mode 3: Micro networks power is provided by a large network, which is considered only for the purpose of minimal cost of power generation.

Minimize the cost of electricity when micro networks run independently.

The micro networks that consist of photovoltaic power generation, non-grain biomass power generation and diesel power generation should give priority to the power supply that has lower cost of power generation when running on the island. So we can achieve the purpose of the smallest cost of electricity.

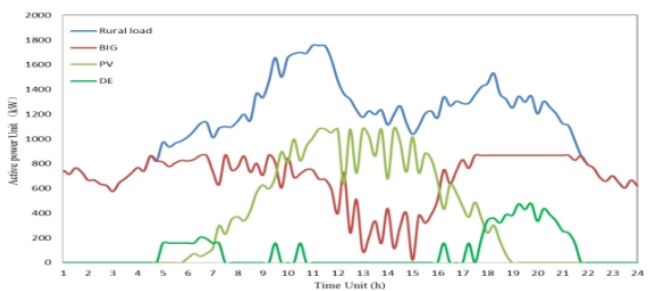

Figure 6. The island summer operation mode

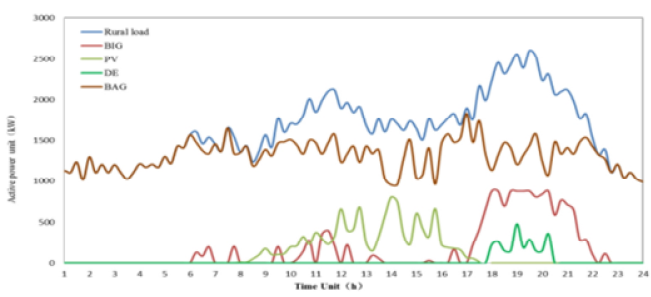

Figure 7. The island winter operation mode

The results of the island mode 1 in summer are shown in Figure 6, the 06: 00-11: 00 period is the early peak of the agricultural load in the day. The PV output increases with the sunshine intensity, when the biogas power generation and the photovoltaic power generation cannot meet the load 
requirements, the diesel is started as a backup load to supplement the power shortage. After 15:00, the output of the PV is gradually reduced, and the biogas output increases, and the maximum output of the biogas power generation is reached at the peak of the 18: 00-22: 00 period. At this time, the diesel power generation is opened to supplement the shortage of biogas power supply and keep adequate reserves. Compared with the mode 1 in summer, the island operating costs are 4612 Yuan that is higher than which of network operation, and the diesel power generation is the higher part. Diesel power generation play a major role in balancing photovoltaic and non-grain biomass power generation, although its cost of electricity generation is high, but its output is stable, and play a temporary support role.

Compared with summer, the load is increased in winter, bagasse power generation just filled the vacant load. It can be seen from Figure 7, load is gradually increased in 07: 00-13: 00 period.

Because the cost of bagasse power generation is lower than which of biogas power generation, and bagasse resources are more abundant, so bagasse power generation is main power, and the biogas power generation is a supplement. On the other hand, the output of bagasse power generation at 13: 00-16: 00 period and 18: 00-21: 00 period fluctuates greatly, and the main reason is that the power network gives priority to the photovoltaic power generation with high randomness. We take the diesel power generation as a backup of island operation. Table 6 shows the island running cost.

The economics of micro-grid operation is a key factor in the development. In summer, the micro-grid cost of mode 1 is higher than that of the model 3 in island operation, while the cost is saved about 5037 Yuan compared with the model 3 in winter, and the operation of each mode is consistent with which in the island. The main reason is that although non-grain biomass power generation costs are low, but when its permeability is not high enough, and there is a high cost of distributed power supply, the micro-grid power generation costs may not be able to effectively reduce, even higher than the cost of mode 3 .

Table6. Island running cost

\begin{tabular}{|l|c|c|c|c|}
\hline Type & $\begin{array}{c}\text { Summer } \\
\text { Costs / Yuan }\end{array}$ & $\begin{array}{c}\text { Summer } \\
\text { Percentage } \\
\%\end{array}$ & $\begin{array}{c}\text { Winter } \\
\text { Costs / Yuan }\end{array}$ & $\begin{array}{c}\text { Winter } \\
\text { Percentage } \\
\%\end{array}$ \\
\hline Biogas & 7393.1 & 0.618 & 1813.9 & 0.104 \\
\hline PV & 8436.1 & 0.308 & 2937.4 & 0.073 \\
\hline Diesel & 5667.7 & 0.074 & 1757.7 & 0.016 \\
\hline Bagasse & $/$ & $/$ & 9377.1 & 0.807 \\
\hline Total & 21496.8 & 1 & 15886.8 & 1 \\
\hline
\end{tabular}

\section{Conclusions}

In order to achieve the goal of minimizing the cost of island operation, the micro-grid model of multi-objective, dynamic and optimal scheduling is established in this paper. Taking the typical light, diesel and non-grain biomass grid as an example, the scheduling results of summer and winter are analyzed and compared, and come to conclusions that the operation cost and electricity price mechanism of single micro source will affect the scheme and effect of dynamic economic dispatch. In addition, adding controllable non-grain biomass power generation to the micro network can be more accurate to develop the feeder plan of power, increase reliability and stability of power grid, reduce the impact to large networks, and provide more jobs by promoting the use of non-grain biomass power generation in rural areas. From the dynamic economic scheduling results, we can get a preliminary judgment. Micro-grid dynamic economic scheduling in this paper can try to rural areas where renewable resources and non-food biomass resources are rich. Building non-grain biomass power generation of Micro network not only alleviates the tension of electricity in rural, but also can provide safe, economical and green power.

Rapid economic growth will drive the increase of load, so promote the use of non-grain biomass power generation is an efficient, economical, environmentally friendly and reliable effective measure in rural and remote areas. In the future, economic growth will put forward higher requirements to 
safety, environmental protection and economy of electricity in rural. Villagers should actively cooperate with the planting, cultivation and collection plan of non-grain biomass resources that is conducive to development of non-grain biomass power generation. The government and the grid should improve the support policies to speed up the development of non-grain biomass power generation, and promote the combination of non-grain biomass power generation projects and construction and transformation of new rural distribution network to create a clean power grid. At the same time, we can adjust the network location which distributed power supply access in to reduce the impact on power quality, and improve the reliability of distribution network with technology of non-grain biomass power generation. We need to point out that the optimal cost of the corresponding operating program is not unique, unified electricity price cannot reflect the difference of purchasing power each time period.

\section{References}

[1] Liu Qiang, Liu Yuanyuan,Song Hongwei. Thermal Performance Analysis of a Biomass-fired Organic Rankine Cycle [J]. Proceedings of the CSEE. 2013,(26): 60-67.

[2] China Electricity Council [EB/OL]. [2013-02-28].

http://www.cec.org.cn/yaowenkuaid/2013-02-28/97882.html.

[3] Xie Guanghui, progress and direction of non-food biomass feedstock supply research and development in China[J].Journal of China Agricultural University, 2012,(06): 1-19.

[4] Xie Guanghui, nature of non-food for the non-food biomass feedstock in China[J].Journal of China Agricultural University, 2013,(06): 1-5.

[5] China electric power research institute institute of biomass energy.Biomass energy and its power generation technology [M]. BeiJing: China Electric Power Press. 2008: 262.

[6] Xu Gang, Tian Longhu, Liu Tong, et al. Strategic Analysis of CO 2Mitigation in Chinese Power Industry [J]. Proceedings of the CSEE. 2011,(17): 1-8.

[7] Xujie,Yuanzhenhong,liu zhuna, et al. The development status,obstacles of biomass industry in china and countermeasures[J]. Acta Energiae Solaris Sinica. , 2012,(S1): 122-128..

[8] LuoYuhe,Ding Lixing. Evaluation of Biomass Power Generation Systems Based on Emergy Theory[J]. Proceedings of the CSEE. 2009,(32): 112-117.

[9] Liu Xiaoyu, Liu Junnan, Tang Xiangang, et al. Comprehensive Power Supply Evaluation of Combined Renewable Energy Applied in Rural Microgrid[J]. East China Eectric Power, 2012,(01): 5-9

[10] Zhou Zhichao,Guoli,Wang Chengshan, , et al.Optimal Planning and Design of a Wind/Biomass/Diesel/Battery stand-alone Microgrid. Automation of Electric Power Systems. 2014,(07): 16-22.

[11] Wang Chengshan, Wu Xiao, Li Peng. Research on Key Technologies of Microgrid [J]. Transactions of China Electrotechnical Society, 2014,(02): 1-12.

[12] Taoqiong,Wu Zaijun,Cheng Junzhao, et al. Modeling and Simulation of Microgrid Containing Photovoltaic Array and Fuel Cell[J].Automation of Electric Power Systems. ,2010,(01): 89-93.

[13] FARRET F A, SIMOES M G. Integration of alternative sources of energy [M]. New York, USA: IEEE Press, 2006: 379-418.

[14] Hong Bowen,Guo Li,Wang Chengshan et al. Model and method of dynamic multi-objective optimal dispatch for microgrid[J].Electric Power Automation Equipment., 2013,(03): 100-107.

[15] Zhang Hao,Ma Aijun, Li Wenbin, et al. Research of the relationship between wind farm output and energy storage[J].Electric Power, 2012,(06): 77-81.

[16] ChenWeimin,ChenGuocheng, Cui Kaiyong, et al. Running Control of Grid-connected Dispersed Generation Systems in Islanding Situation.. Automation of Electric Power Systems. 2008,(09): 88-91. 
[17] McCarl B A. McCarl GAMS user guide[M].24.0 ed.USA:GAMS Development Corporation, 2013.

[18] A.Wachter. An Interior Point Algorithm for Large-Scale Nonlinear Optimization with Applications in Process Engineering[D]. Carnegie Mellon University, Pittsburgh, PA, USA, January 2002.

[19] Tang Yunchuan, Zhang WeifenG, Ma Lin, et al. Estimation of biogas production and effect of biogas construction on energy economy[J]. Transactions of the CSAE, 2010,(03): 281-288.

[20] Wang Yanqin, Liu Ying, Yao Li. et al. Effect of Different Heat Preservation Measures on Digester Temperature and G as Production in Northern Winter[J].China Biogas,2010,(05): 31-34.

[21] Fu Xiuqin, Chen Yuai, Deng Liangwei.Volume Choosing Of Piggery Waste Treatment[J].China Biogas, 2002,(02): 25-28.

[22] Zhang Cuili, Li Tiebing, Bu Dongsheng,,et al. Biogas yield and its relations with the duration and temperature of mixed an aerobic fermentation of livestock dungs and wheat straw. [J]. Chinese Journal of App lied Ecology, 2008,(08): 1817-1822. 